ISSN: $2471-6774$

\title{
Soilless Agriculture a New and Advanced Method for Agriculture Development: an Introduction
}

\author{
K A El-Kazzaz ${ }^{1}$ and AA El-Kazzaz ${ }^{2 *}$ \\ ${ }^{1}$ Agricultural Engineer, Head of Hydro Valley Company, Cairo, Egypt \\ ${ }^{2}$ Department of Plant Biotechnology, National Research Centre, Egypt
}

Submission: December 19, 2016; Published: January 04, 2017

*Corresponding author: AA EI-Kazzaz, Department of Plant Biotechnology, National Research Centre, 12622, Dokki, Giza, Egpyt,

Tel: +201119508406; Email: profelkazzaz3@yahoo.com

\begin{abstract}
Agriculture out of the soil is to use any means that will cultivate and plant development without entering the soil as a mediator for agriculture, where cultivated plants in isolation from the soil as long as the system used allows to strengthen the plants and provide water needed for growth and nutrients as it is the system followed for growing plants in the natural soil environment with irrigated nutrients intravenously instead of plain water and may be used a solid material such as gravel, sand, peatmoss, perlite and vermiculite in some cases as supporting mediators. Agriculture outside of soil is including hydro agriculture (Hydroponics), aqua agriculture (Aquaponics), aerobic agriculture (Aeroponics) as well as agriculture using supportive mediators. Benefits of soilless cultures include the reservation of cultivated lands for main crops; save not less than $90 \%$ of irrigated water; use nearly recycled fixed amount of water; most vegetable crops succeed and give the highest productivity in soilless agriculture than the ordinary agriculture; It can be run in various places such as balconies, roofs of buildings, various greenhouses and lands unsuitable for cultivation; the provision of fertilizer materials, where it's used rationed amounts calculated accurately nutrients according to the plant requirements; Ease of dealing with plants and ease of conducting the required protection operations against various pests; Despite the increase in the constituent unit cost of soilless culture, but the large amount of production offset this cost in a short time. Soilless culture is a method of cultivation of new and advanced and requires us to search for human cadres have the ability to qualify for this work and is a rare, unfortunately.
\end{abstract}

Keywords: Hydroponics; Aquaponics; Aeroponics; Soilless cultures; Agriculture

\section{Introduction}

Although several published works on cultivation plants in soils, few of these concentrate on planting plants in soilless cultures. The presented work is an overview of the systems of agriculture out of the soil. However, soilless agriculture offer a way to overcome the shortage of the normal amount of water needed to grow plants. Agriculture without soil, in fact, historically dates back to several hundred years BC since the civilization of ancient Egyptian, the Chinese and other cultures [1]. The Aztecs started a method of suspended gardens based on hydroponics at Lake Tenochtitlan during the $10^{\text {th }}$ and $11^{\text {th }}$ centuries $[2,3]$. There are various techniques of soilless agricultures have being recently used. Such techniques are including Hydroponics, Aquaponics, Aeroponics as well as agriculture using supportive mediators. The soilless agricultures can be accessed on various kinds of places such as balconies, roofs, greenhouses and lands unsuitable for cultivation. Such kinds of agriculture operate under control conditions in order to obtain higher productivity and higher incomes. Despite the rise within the constituent cost of soilless culture, however the massive quantity of production offset this value in an exceedingly short time. Soilless culture could be a technique of cultivation of recent and advanced and needs to go looking for human cadres have the power to qualify for this work and could be a rare, sadly. In this regard, it will be reviewed these techniques briefly focus on the following paragraphs.

\section{Historical steps of soilless agriculture}

As it was remembered in introduction, soilless agriculture was used and recorded in several ancient civilizations but no information was recorded about it. However, the earliest published work on growing terrestrial plants without soil was the 1627 book, Sylva Sylvarum by Sir Francis Bacon, father of the scientific method, which he nominated it "water culture". 
However, Robert Boyle, the Irish scientist, in 1666 had been described the first experiments on growing plants with their roots submerged in water. In 1699, John Woodward published his water culture experiments with spearmint and found that plants in less-pure water sources grew better than plants in distilled water. Mineral nutrient solutions for soilless culture of plants were first perfected in the 1860s by the German botanists, Julius von Sachs and Wilhelm Knop through experiments conducted at 1842 and 1895 respectively. The first proposal for a commercial water culture system was made in 1929 by Professor William Frederick Gericke of the University of California at Berkeley. The term "hydroponics" was coined by Gericke 1937 to describe the growing of crops with their roots in a liquid medium. Moreover, in 1940 Gericke wrote the book, Complete Guide to Soilless Gardening. However, two others of plant nutritionists at the University of California named Dennis R. Hoagland and Daniel I. Arnon since 1938 had developed nutrition solution named Hoagland solution used for hydroponics until now. Since, 1930, on Wake Island, a rocky atoll in the Pacific Ocean used as a refueling stop for Pan American Airlines, Hydroponics was used to grow vegetables for the passengers. Hydroponics was a necessity on Wake Island because there was no soil, and it was prohibitively expensive to airlift in fresh vegetables. In the 1960s, Allen Cooper of England developed the Nutrient Film Technique. In recent decades, many companies world widely are appearing and strongly working in soilless agriculture. Moreover, NASA has done extensive hydroponics research for their Controlled Ecological Life Support System (CELSS) [1-6].

\section{Designation and function of soilless culture}

Soilless culture is a man-made suggests that of providing plants with support and a reservoir for nutrients and water. In this regards, Savvas et al. [6], reported that Soilless culture can be defined as "any method of growing plants without the use of soil as a rooting medium, in which the inorganic nutrients absorbed by the roots are supplied via the irrigation water". The only and oldest technique for soilless culture may be a vessel of water during which inorganic chemicals melted (nutrient solution) to produce all of the nutrients that plants need. Typically is known as solution culture or water culture.

The function of soilless cultivating method is stimulating plant growth while controlling the quantities of water, mineral salts and most important, dissolved oxygen. The basic concept is quite simple. When roots are suspended in moving water, they absorb food and oxygen rapidly. If the oxygen content is insufficient, plant growth will be slow. But if the solution is saturated with oxygen, plant growth will accelerate. Therefore, the grower's task is to balance the combination of water, nutrients, and oxygen, with the plan's needs, in order to maximise yield and quality. For the best results, a few important parameter need to be taken into account; temperature, humidity and $\mathrm{CO} 2$ levels, light intensity, ventilation, $\mathrm{pH}$ and the plant's genetic make-up. Essentially this is what any conscientious gardener would do. Agriculture outside of soil is including hydro agriculture (Hydroponics), aqua agriculture (Aquaponics), aerobic agriculture (Aeroponics) as well as agriculture using supportive mediators. However, In Soilless culture plants did not need soil but they need to be supplied with minerals Nitrogen $(\mathrm{N})$, Potassium (K), Phosphorous (P), Calcium (Ca), Magnesium $(\mathrm{Mg})$, Sulphur (S), Iron (Fe), Manganese (Mn), Copper $(\mathrm{Cu})$, Zinc $(\mathrm{Zn})$, Molybdenum (Mo), Boron (B), Chlorine (Cl) and vitamins also they need water, light, carbon dioxide, oxygen at their root zone. It is an art.

\section{Types of soilless cultures}

There are two main types of soilless culture; closed soilless culture and open soilless culture.

Closed soilless culture type: In closed soilless frameworks the dissolved supplements are recycled and the supplement concentrations are observed and balanced in like manner. Keeping the supplement adjust in such hydroponic frameworks is a test and the dissolved supplements must be examined and dissected in any event once every week. The dissolved supplements must be balanced by results. If there is not oversaw appropriately, the dissolved supplements may escape of the balance. Closed soilless frameworks incorporate both basic and advanced soilless culture frameworks.

Open soilless culture type: In open soilless frameworks a new dissolved supplements is involved for every irrigation cycle. The dissolved supplements are normally conveyed to the plants utilizing the dripping framework. In open soilless frameworks a sufficient keep run-off must be kept up with a specific end goal to keep supplement adjust in the root zone. Every soilless culture utilizes just the substrates and dribble frameworks are has a place with open soilless culture. However, there is a drip system used as closed system in case of use reservoir for recirculating the nutrient solution.

\section{Soilless culture systems that divided from both soilless culture types}

The following systems are belonging to closed soilless culture in brief

Hydro agriculture (Hydroponics): Hydroponics (i.e., "water working") is simply the growing of plants without soil. Plants don't need soil, but they do need the vitamins and minerals that soil can provide for them. Plants also need light, water, carbon dioxide and oxygen at the root zone. In hydroponics, plants are grown in an inert medium such as rocks or coco coir fiber, and they are fed a solution containing a perfected mix of primary, secondary and micro-nutrients. Almost any kind of plant can be grown hydroponically, including veggies, herbs, fruits and flowers. Hydroponics is world widely used by farmers and growers.

Hydroponics provides an advantage over soil growing for several reasons [7,8]. Plants can be grown year-round since climate conditions can be controlled in a greenhouse. Because 
their roots do not need to reach for nutrients, the plants can be grown closer together. The plants grown are significantly larger because of so many available nutrients and not having to waste time growing extensive root systems. This makes the yields bigger. The nutrient solution also keeps the same amount of nutrients available all the time, whereas soil tends to "wear out" as the nutrients are taken up. The combination of all these things makes hydroponics plants more productive than soil growing plants. Many farmers in various places are beginning to switch over to hydroponics for all of these reasons. The concern about water use is also big reason hydroponics is becoming more popular - it significantly conserves water over the usual growing methods. The following Figures from 1 to 5 show some of the kinds of hydroponics mainly used, but any person can put his own design according to his need and the kind of plants according to the main target and the aim of hydroponics function. The following is a brief of five systems are mainly used.

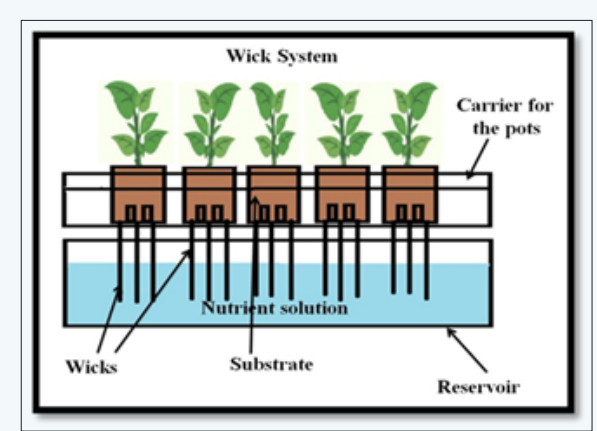

Figure 1: Shows the wick system.

Wick system: The wick system (Figure 1) is the simplest of all types of hydroponic systems. That's because traditionally it doesn't have any moving parts, thus it doesn't use any pumps or electricity. However, the wick is the connecting part between the potted plant and food solution in the existing reservoir. Because it doesn't need electricity to work, it's also quite useful in places where electricity can't be uses, or is unreliable. The wick system is an easy type of system to build when first learning about hydroponics, and/or you just your want to get your feet wet first. This type of hydroponic system is also often used by teachers in classrooms as experiments for kids. In wick system the plants are cultivated in substrate.

Nutrient film technique (NFT): The nutrient film technique (Figure 2) is recirculated design to run highly oxygenated dissolved nutrients continuously over the roots of plants through a set of channels, typically grown in baskets hanging in a PVC pipe. The solution is pumped from a holding tank, through irrigators at the top of every sloping pipe and the run-off from the bottom of the channels is returned to the tank. Thus, the nutrient solution is continuously recycled. It is possible to make the angle of the pipe smaller and add an overflow pipe similar to what's in an off and flow system. This would serve to provide a reservoir of nutrients that would remain in the event of a power or pump failure. Because of the confined space of a PVC pipe and the requirement for nutrients to continuously flow over the roots, the nutrient film technique is particularly well suited to plants that have small root balls such as lettuce, strawberries, and herbs.

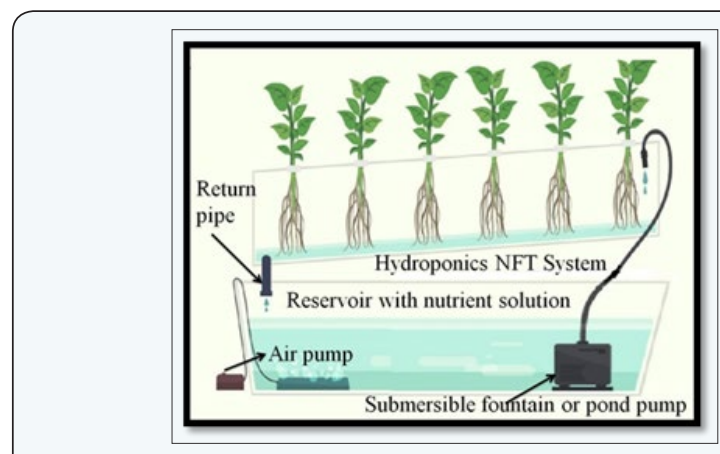

Figure 2: Shows the Nutrient Film Technique (NFT).

Water culture or deep water culture (DWC): Water culture or deep water culture is the straightforward form of hydroponics systems (Figure 3). Plants are floating by float platform on a bath of hydroponic nutrient solution. Oxygen is supplied by an air pump that runs continuously. A water culture system can easily be set up in glass basins, (fish ponds), plastic boxes, ice boxes, Concrete basins or in engraved basins covered with polypropylene sheets. Since the plants are floating and continuously in contact with the nutrient solution, there is no risk of damage to plants in the event of a power outage or stop the air pump. The most convenient plants in this system are Lettuce, strawberries, and herbs grow particularly well in this system.

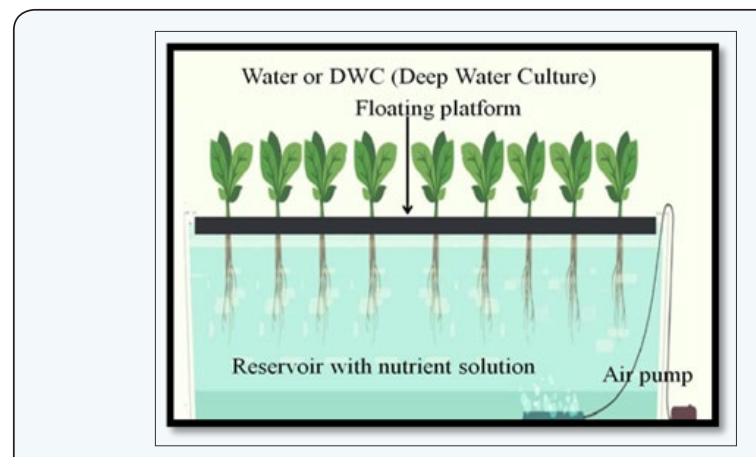

Figure 3: Shows the deep water culture system.

Drip system: Drip hydroponic system (Figure 4) is at least two containers, one on top or higher than the other. Plants are located in the top container, while the nutrient solution is in the bottom container. The nutrient solution is pumped up to drips located by the stem of each plant with a water pump, and an aquarium air stone is used to oxygenate the water. The nutrients filter down to the plant roots and are passed back to the bottom container. Typically both the water and air pumps run continuously with this type of system. A crop of almost any plant will grow well with this system. Plants with large root balls are particularly suited to drip systems. However, the plants are grown in supportive mediators. 




Figure 4: Shows Drip system (DWC).

Ebb and flow systems: Ebb and flow system (Figure 5) is another inexpensive type of hydroponic setup. The setup is very similar to the drip system, where there are two containers, the one on top containing the plants in pots with substrate, and the one on the bottom containing the nutrient solution. Rather than the nutrient solution being passed slowly to drippers at the stem of each plant, the nutrients are pumped in large volumes into the top container, flooding the container. An overflow pipe determines the height of the nutrients, typically to where the roots begin at the base of the stem, with excess liquid being recirculated through the overflow pipe back to the bottom container. With ebb and flow system, the pump is switched on and off intermittently (perhaps 30 mins on, 15 mins off), to flood the grow tray periodically. When the pump is switched off, all of the nutrients are siphoned out of the grow tray via the pump line. The emptying period allows for oxygen to reach the roots, and for this reason an air stone is not absolutely required for ebb and flow systems. As with drip systems, almost any plant will grow well with this type of system. Plants with large root balls are also particularly suited to off and flow systems.

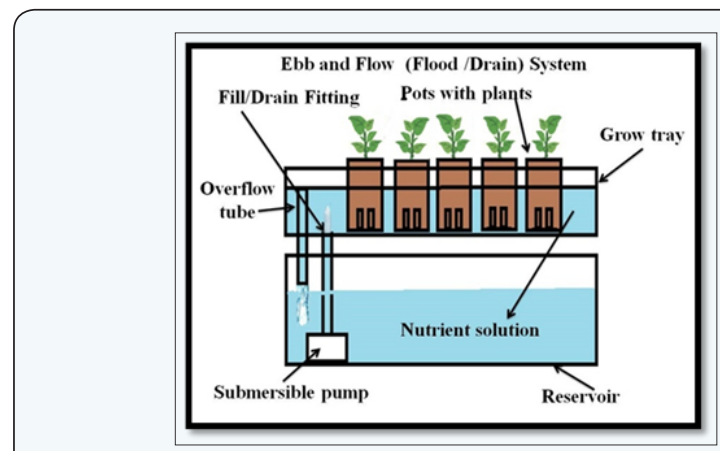

Figure 5: Shows the Ebb and flow (Flood and Drain) system.

\section{Aeroponic systems}

The aeroponics system is belong to closed soilless culture system (Figure 6) is probably the most high-tech type of hydroponics system [8]. In this system sealed root chambers used as reservoir for nutrient solution and the plants above the reservoir cover (polystyrene or other material) must be supported or hanged through holes in the expanded cover, hence the roots hang in the air under the reservoir cover and are misted with nutrient solution found in the reservoir by stressful pump to cover all area around the root with nutrient solution mist. The misting is usually done every few minutes around the hanged roots. Because the roots are exposed to the air, the roots will dry out rapidly if the misting cycles are interrupted. A timer controls the nutrient pump much like other types of hydroponic systems, except the aeroponics system needs a short cycle timer that runs the pump for a few seconds every couple of minutes. However, the chamber must be lightless materials from everywhere, so that the roots are in darkness functionally good also to inhibit algal growth that impedes the growing plants and pollute the system.



In this system, nutrient solution sprayed as a fine mist in sealed root chambers. The plants are grown in holes in panels of expanded polystyrene or other material. The plant roots suspended in midair beneath the panel and enclosed in a spraying box. The box sealed so that the roots are in darkness (to inhibit algal growth) and in saturation humidity. A misting system sprays the nutrient solution over the roots periodically. The system normally turned on for only a few seconds every 2-3 minutes. This is sufficient to keep roots moist and the nutrient solution aerated.

There are three sorts of aeroponics frameworks. The first framework is high pressure aeroponics frameworks don't generally utilize a water pump because of the various cycle (on/off) times required. They as a rule comprise of a two sided tank with an elastic divider. The supplement arrangement is in one side and air in the other. At that point an air compressor is utilized to pressurize the tank. A water line from the supplement arrangement side races to the clouding heads, and a solenoid is utilized to open and close a valve in the water line at exact times utilizing a cycle clock. The genuine aeroponics framework utilizes high pressure (60-90 psi). The second framework is low pressure aeroponics frameworks (soakaponics) are what the vast majority are alluding to when they say aeroponics. Low pressure frameworks utilize standard submersible water pumps, yet at the same time require a decent measure of water weight or the water will simply stream out of the sprinkler/mister heads. The more sprinkler heads you're utilizing, the more water pressure you will require. Sadly submersible pumps don't give a psi rating to look at. They just give you gallons every hour (GPH) 
and head tallness, and GPH is a measure of volume, not pressure. Your best pointer of water weight is the "head stature" rating. It takes pressure to pump water up, so the more GPH it can pump higher, the more water pressure it will have. In any case, the vast majority allude to low pressure splashing frameworks as aeroponics frameworks as well. The third framework is Ultrasonic foggers that make a fog in aeroponic frameworks. While they do make a fog with a little water bead measure, there is next to no genuine dampness in the fog/mist. The fog made from ultrasonic foggers likewise tends to drop to the base of the holder. Ensuring the roots is totally secured by the fog constantly. Another issue with utilizing foggers is that the plates tend to stop up with mineral form. The main plates that have appeared to work with any dependability are the more costly Teflon heads. They can once in a while be cleaned utilizing white vinegar, or dilute and $\mathrm{pH}$, and wiping them off with a Q-tip. A few producers have joined utilizing ultrasonic foggers alongside the low weight aeroponic plan in a similar framework [8].

\section{Aqua agriculture (Aquaponics)}

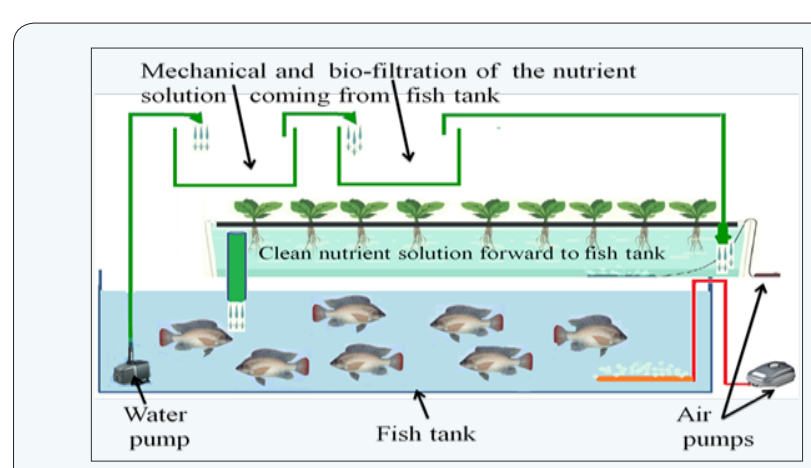

Figure 7: Clears the target steps of Aquaponics culture with hydroponics deep water culture (Can be replaced by NFT system or Media filled beds system or all systems together can be worked).

Aquaponics is a system of aquaculture (Figure 7) in which aquatic animals such as snails, fish, crayfish or prawns are grown in tanks with combination of hydroponics in which plants are grown in water in a symbiotic environment [911]. In aquaculture, the aquatic animal's excretions are raised and accumulated in the water, increasing toxicity according to ammonia foundation as toxic byproducts for aquatic animals; hence, the aquaculture must be cleaned from that toxic material. In an aquaponics system, water from an aquaculture system is passing to hydroponics system where the toxic by-product are broken down by Nitrifying bacteria that live on the surface of the grow bed media initially into nitrites and subsequently into nitrates, which are utilized by the plants as nutrients, and the water is then cleaned and passing back to the aquaculture system. However, the used water passed through a biofilter a place where the nitrification bacteria can grow and convert ammonia into nitrates, which are usable by the plants. As existing hydroponic and aquaculture cultivating procedures constitute the foundation for all aquaponics frameworks, the size, complication, and sorts of foods grown in an aquaponics framework can differ as much as any framework found in either particular cultivating discipline. These are the most commonly used type of aquaponics systems; 1- Media filled beds are the simplest form of aquaponics, they use containers filled with rock medium of expanded clay or similar. Water from a fish tank is pumped over the media filled beds, and plants grow in the rock media. This style of system can be run two different ways, with a continuous flow of water over the rocks, or by flooding and draining the grow bed, in a flood and drain or ebb and flow cycle. 2- Nutrient Film Technique (NFT) is a commonly used hydroponic method, but is not as common in aquaponics systems. In NFT systems, nutrient rich water is pumped as very thin film down small enclosed gutters. Plants sit in small plastic cups allowing their roots to access the water and absorb the nutrients. NFT is only really suitable for certain types of plants, generally leafy green vegetables, however, larger plants will have root systems that are too big and invasive, or they become too heavy for the lightweight growing gutters. 3- Deep Water Culture (DWC), works on the idea of floating plants on top of the water allowing the roots to hang down into the water. This can be done in a number of ways. This method is one of the more commonly practiced commercial methods. DWC can be done by floating a foam raft on top of the fish tank; however a more common method is to grow the fish in a fish tank and pump the water through a filtration system, and then into long channels where floating rafts filled with plants float on the water surface and extract the nutrients. However, this system is considered as closed soilless culture whereas a recirculating system for the nutrient solution is occurred.

Figure 7 clears the target steps of Aquaponics culture with hydroponics deep water culture (Can be replaced by NFT system or Media filled beds system or all systems together can be worked).

\section{Substrate culture (Growth medium)}

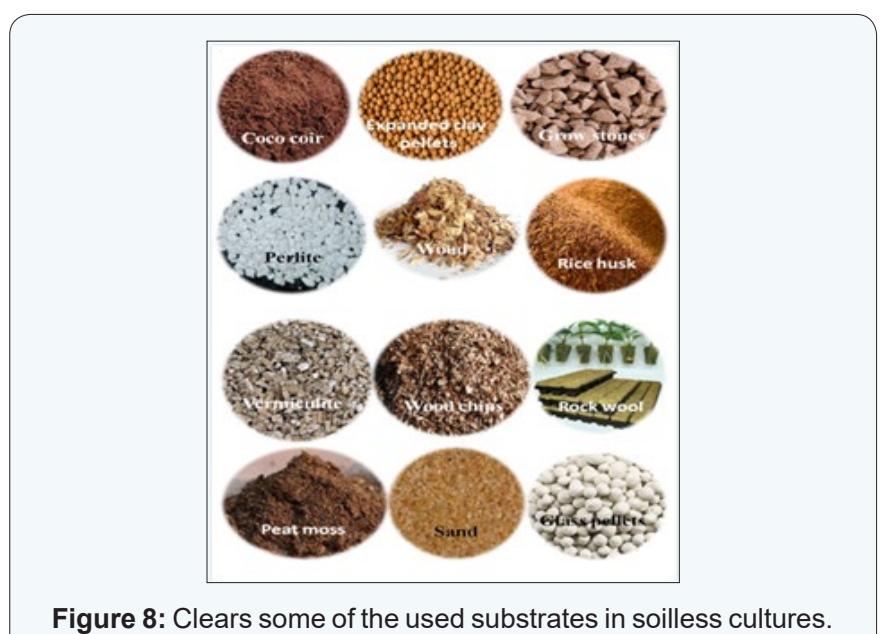

Figure 8: Clears some of the used substrates in soilless cultures.

Growth medium is the substitute for soil in soilless culture systems. In this system, a solid medium provides support for the plants. The functions of growth medium are to provide the roots 
with oxygen bring the water and dissolved nutrients in contact with roots via irrigation system through the media, allowed to run to waste to recirculate the solution through the system and to steady the plants as supportive mediators so that they do not fall over. There are various substrates (Figure 8) that used as growth medium are consisting of inorganic (natural; expanded clay, glasswool, gravel, perlite, pumice, rockwool, sand, sepiolite, vermiculite, volcanic tuff and zeolite or synthetic; foam mats, hydrogel and plastic foam) or organic (bark, coconut coir, coco soil, fleece, marc, peat, ruffia bark, rice husk, sawdust and wood chips) [12].

The substrate culture systems divided according to drainage procedure into the following two major systems [13]. As remembered before, in most soilless cultures that used substrates without reservoir for recirculating the nutrient solution are belong to open soilless cultures, therefore, more care about the feeding the plants must be taken because the irrigation water with the supplements dominantly lost. The open substrate culture seems to be more promising due to its high adaptability to the farmers' conditions $[14,15]$. In countries where hydroponics is applied commercially, open hydroponics cultivation systems have created pollution problems resulting in a consequent transition to closed systems. The closed substrate systems increase water, nutrient and pesticide use efficiency and decrease their impact on the environment but a specific system needs to be developed for each crop $[16,17]$.

Properties of substances used in soilless culture: There are many stuffs are used for building the growing systems for soilless culture, such as asbestos, aluminum, concrete, corrugated sheets, polyethylene, polypropylene, polystyrene foam, PVC, steels and any material that comes to mind. All these stuffs must have sustainability characteristics [12].

Technical specifications of the materials used to create the systems: However, the specifications of these materials must exhibit the followings; 1 - No outflow during installing and usage process and possibility of evaluating possible outflows. 2- No damaging volatilization of damps or substances. 3Resistance to vapor that used for sanitation, UV radiation and pesticides. 4- Ensure rewind materials to suppliers for recycling. 5- Low costs. 6- Have no reactions with each other's or any used solutions (inert). 7- Also, Metallic materials must be coated with weatherproof materials against interact with any solid materials, liquid or gaseous.

Technical specifications of supportive substrates: Often hydroponics as a technique of soilless culture is using only water, with no substrate. This is true for NFT or Aero-hydroponics, which use no media, or just enough to act as a plant support. But growers working with Drip Irrigation, Deep Channel NFT, or Ebb and Flow, will use more or less supportive substrate depending on the growing system they choose. Supportive substrates must have the following properties [12]
1- Aeration and drainage. 2- Applicable in natural form without need for processing. 3- Can be mined or produced by the industry. 4- Cation exchange capacity (buffering action). 5Easy to use and Environmental and health hazards. 6- Free from grit, heavy metals and radioactive pollutants and Cleanliness. 7Has constant quality (no decrease of physical properties during use). 8- Having a lifespan for at least three years. 9- Hydrophilic. 10- Inert (no reaction with the nutrients). 11- Low cost. 12Low density. 13- Have neutral pH. 14- Porous. 15- Recyclable or destroyed without hazard. 16- Resistant for sterilization several times without structural quality change. 17- Pest free. 18- Stability of organic matter. 19-Have water retention capacity and water to air ratio.

Another essential aspect to keep in mind is the close relationship between the supportive substrate and the irrigation cycles applied whereas some of them will retain much more moisture than others. Many supportive substrates are in the markets that meet the above demands with label specifications.

\section{Plant Necessities}

\section{Growth demands}

Many factors, such as nutrition, light, heat, air, $\mathrm{pH}$ and salinity affect plant growth, whether it was developing in the soil or soilfree systems. In agriculture without soil Systems, nutrition and water are permanently available to the plants, whether inside or outside doors and therefore the plants never stressed. However, in outdoor, the sun light and air are obtainable but for indoor systems, adequate light sources such fluorescent lights, grolights, Metal halide lamps or sodium vapor lamps must be used. All soilless culture systems must provide available oxygen using good air circulation at the root zones to keep them alive. Healthy roots which are white in color are responsible for absorption of nutrients and water for growing the plant. However, it must be good air circulation for the indoor systems around the plant leaves to carry out the photosynthesis. However, root zone must be worm enough to keep the root zone to $20-22 \mathrm{C}^{\circ}$ as possible to prevent ant disorder can be done for the cultivated plants.

\section{Nutrient solution}

The success or failure of agriculture without soil depends on the existence of balanced nutrient solutions and appropriate for all stages of plant growth. Agricultural fertilizers are sold through stores that sell agricultural products and must choose the right fertilizer for soilless cultures that contain all 13 elements necessary for plant growth. It is crucial to follow instructions of the dilution rate recommended on the label and to test the recommended solution to be sure the $\mathrm{pH}$ is between 5 and 6. Simple $\mathrm{pH}$ test kits and $\mathrm{pH}$ modifiers are available wherever fish supplies are sold. Depending on the stage of plant development, some elements in the nutrient solution will be depleted more quickly than others. Therefore, it is appropriate to measure the lack of elements of the farming system without soil every two weeks, and to provide this shortage, also, make 
sure that the nutrient solution is kept at the original volume. It must compensate the lack of water as the result of in the output cultivated plant consumption and as a result of evaporation during cultivation time in the system. Due to lack of water in the system, the concentration of nutrients is increase and can harm the root system and its function, therefore, it must compensate for this deficiency by adding new clean filtered water to raise the nutrient solution to its original concentration. Be sure to use nutrients designed for Hydroponics in a Hydroponic system. The composition of elements in nutrients designed for soil is very different from that for Hydroponics because soil grown plants get most of these elements from the soil. With Hydroponics there is no soil to get the elements from, so the two are very different in composition because they are not designed to be a complete plant food and they may not water-soluble. For example, Nitrogen in the form of urea is not immediately available to a plant in hydroponics because urea is not soluble in water. For this reason Nitrogen must be delivered in its Nitrate form in order to be utilized in hydroponics. One thing that is often over looked when it comes to nutrients is the nutrient solution temperature. The roots of plants grow underground in nature and to duplicate what they would receive in nature it is very important to keep the root zone to $20-22^{\circ} \mathrm{C}$. That's not to say if the nutrient temp reaches $23{ }^{\circ} \mathrm{C}$ or $23.5^{\circ} \mathrm{C}$ the plants will die, but it should be kept as close to $20-22{ }^{\circ} \mathrm{C}$ as you can. Plants with nutrient tempters too high can have problems including (but not limited to) flowers turning yellow and falling off, damaged fruits and a lack of new growth [18].

\section{Water Quality}

One of the main elements of the success of farming systems without soil is water availability and quality. There are many sources for water availability from lakes, rainwater, rivers and underground reservoirs or from other treatments. However, water must be of high quality free of pathogens as determinant factors for the success of agriculture without soil [19].

\section{Water Disinfection}

One of the disadvantages of the closed systems is the risk of a rapid dispersal of soil-borne pathogens by the recirculating nutrient solution. To eliminate these pathogens, several disinfection methods can be used and the followings are some of them:

\section{Ozone treatment}

Ozone treatment can be used to disinfect the drain water. Ozone is the second most powerful sterilants in the world and its function is to destroy bacteria, viruses and odors. An ozone supply of $10 \mathrm{~g} / \mathrm{h} / \mathrm{m} 3$ water with an exposure time of $1 \mathrm{~h}$ is sufficient to kill all pathogens [20].

\section{UV disinfection}

Another way to disinfect the drain water is the use of UVradiation. Ultra-violet radiation (or UV) is a proven process for disinfecting water, air or solid surfaces that are microbiologically contaminated. For eliminating bacteria and fungi an energy dose is recommended of $100 \mathrm{~mJ} / \mathrm{cm} 2$. For viruses a dose of $250 \mathrm{~mJ} /$ $\mathrm{cm} 2$ is recommended. The advised dosage of $100 \mathrm{~mJ} / \mathrm{cm} 2$ to control Fusarium gave adequate control at $14 \%$ transparency. However, at $8 \%$ transparency $110 \mathrm{~mJ} / \mathrm{sq} . \mathrm{cm}$ was needed; and at $4 \%$ transparency, more than $174 \mathrm{~mJ} / \mathrm{sq} . \mathrm{cm}$ was required. For Fusarium control, the grower has the option of diluting the water, or increasing the UV radiation [21-23].

\section{Heat treatment}

When heat treatment is applied, a solution is heated for about 30 seconds to a temperature of $95^{\circ} \mathrm{C}$. At this temperature all pathogens are killed [24]. A disadvantage of heat treatment is the consumption of gas. Also warm drain water contains less oxygen.

\section{Slow sand filtration}

For several years commercial growers have used a slow sand filtration installation to eliminate pathogens [23-27]. Sand filtration is frequently used and a very robust method to remove suspended solids from water. The filtration medium consists of a multiple layer of sand with a variety in size and specific gravity. Sand filters can be supplied in different sizes and materials both hand operated or fully automatically.

\section{Electrolysed water}

In agriculture, the principle application is as a biocide, signifying 'life-executing' specialist. It is utilized to split down the foul develop in hydroponic lines that frequently contains microorganisms, contagious spores and different organisms. It is likewise utilized effectively for sterilization of seeds, blooms, organic products, vegetables, hardware and packing materials. Sooner rather than later it might be utilized for malady control as a part of nurseries. The official term for this procedure is Anodic Oxidation (AO), and the machine that makes electrolysed water is an AO-unit. Different names for electrolysed water incorporate EW, hydrolysed water, electrically enacted water, electrochemically delivered water, actuated water, dynamic water (and that's only the tip of the iceberg) [28].

\section{Hydrogen peroxide}

Hydrogen peroxide treatment is a much less expensive contrasting option to ozone, UV and layer filtration sterilization. Be that as it may, it is a feeble oxidator. While the execution is enhanced by including a powerless corrosive, it is still not sufficient to take out all pathogens. High measurements (400 ppm) are expected to take out infections, however it was found that a little rate of nematodes survived treatment $(0.3 \%)$, and these were fit for tainting plants. There are a few hydrogen peroxide items available have great impact for particular pathogens including Pythium and Fusarium [28].

\section{Membrane filtration}

Membrane filtration can be separated into inverse osmosis (RO), hyper-, nano-, ultra- and micro-filtration relying upon the 
pore measure of the membrane. They are costly and inclined to gagging after some time. Remedy pre-treatment of supply water is fundamental to expand the life span of membranes. The predetermined necessities were that the micro-filtration unit should have been ready to treat no less than $20,000 \mathrm{~L} /$ day and to screen to a pore size of 0.2 microns. Microfiltration is practically identical in expenses to synthetic treatment alternatives however without the potential perils and without affecting on the nutrient solution. In any case, microfiltration seems uneconomical for smaller enterprises [28].

\section{Chlorination}

Chlorination is the most widely recognized type of cleansing utilized by hydroponic cultivators. It is cheap and promptly accessible. Chlorine is the only biocide that can be lawfully added to nutrient solution. Calcium hypochlorite $(\mathrm{Ca}(\mathrm{OCl} 2))$, normally known as 'pool chlorine', is the most widely recognized disinfectant utilized by the producers. Without going into the science, chlorine's capacity to slaughter smaller scale living beings comes about because of its solid oxidizing power and the interruption of the working of the miniaturized scale living beings. However, if the chlorine sufficiently strong, it will execute all pathogens with which it comes into direct contact. This is useful for cleaning water and recouped nutrient solution. However, the used concentration must be acquired because if it is used at highly strength, it will also attack and kill plant roots. Moreover, it is not systemic so it won't kill systemic pathogens which have attacked plant roots creating sickness [28].

\section{Advantages and Disadvantages of Soilless Cultures}

There are published papers from few years ago that stating the advantages and disadvantage of soilless cultures in the following brief points [12].

\section{Advantages of soilless cultures}

Production augmentation: The application of soilless culture approximately increases the yields as the result of the precise control of the growth elements to the plants such as nutrition, $\mathrm{pH}$, oxygen, carbon dioxide, light and temperatures. However, increasing the yield using soilless cultures will help the offset the initial and any additional costs of the soilless cultures. Soilless culture produced vegetables can be of high quality and need little washing.

Water control: In most kinds of soilless culture the uses of irrigation water are accurately controlled with extremely less amount as compared with normal irrigation in the case of traditional soil cultures. It save much needed labor and time for checking, cleaning irrigation nozzles and frequent examination of trippers which easily can be blocked by calcium carbonate or other compounds that can be eliminated by acidification of nutrient solution or by pretreatment of irrigation water and that need more costs, labor and time.

Monitor of plant nutrition: The nutrition elements are used as solution forms in accurate amounts as the plant needs and not in Hugh amounts as in the normal plantation. In soilless culture, the harmful elements to plants above certain dosages can be kept within safe dosages. However, there is distribution uniformity of nutrition elements only for all the plants in water cultures. PH and E.C. of the nutrient solution can be controlled according to the requirement of the crop and environmental conditions and that is strongly difficult and expensive in the case of normal soil cultures.

Purge practices: Soilless culture is occurred under controlled conditions and that led to avoid spreading of weeds, diseases and insects therefore no need for using the pesticides which finally pollute the environments as used in soil cultures and that mean less labour and less costs.

Monitor root surroundings: In soilless culture, it is easily to control the surrounding environmental and root temperature and supplying roots by oxygen.

Crop diversity: In soilless culture, the interval time between crops is nearly null set because the absence of cultivation operation as in soil cultivation therefore, multiple crops cultivated per year and that mean increasing income.

Agriculture of land inappropriate: Agriculture without soil provides an idealistic process for plant cultivation when there is no appropriate land empty of pathogens and salinity is available.

Alleviation of labor requirements: In soilless culture, all cultural practices of soil cultivation such as soil sterilization, weed control and others can be excluded in soilless culture and that save the labor input and the needed time of work.

\section{Disadvantages of soilless cultures}

High capital investment: The initial cost of building the system of soilless culture is high, but the fast and big yield production offset such costs rapidly in the firstly 3-4 years from the beginning of the system if all things running ok.

The shortage of technicians and skilled labor: Agriculture without soil suffers from a shortage of workers and trained professionals.

The risk of Pathological Injuries: Morbidity in open systems of soilless culture is few whereas in closed systems be great and that need a big care and strong sanitation.

\section{Prospective and Conclusion}

Soilless cultures consider as a new developed technique for agriculture development but it is not simple technique. However, there is lack of technical background of the new technique among growers and horticulturists in many countries and well trained employs are needed. Moreover, most substrates are internationally markets, so they are expensive. Therefore, it is better to look locally about not expensive good substrates. The growers can adept the soilless systems according to their needs, the place of the system and according to their potential cash. The system in any case need to take strong care and observation for 
the parameters needed for the good growth of the plants such as nutrient concentrations, light, oxygen around the plants root zone, water quality, $\mathrm{pH}$, disinfection, temperature of the solution and more.

In conclusion, one might say that, there is extensive advance has been made as of late in the improvement of monetarily suitable soilless systems and there is a generally wide business applications now in Countries that applied farming innovations.

\section{References}

1. Gruda N, Prasad M, Maher MJ (2004) Soilless culture. In: Lal R (Ed.), Encyclopedia of Soil Science. Taylor \& Francis (Marcel Dekker), Inc., New York, USA.

2. http://home.howstuffworks.com/lawn-garden/professionallandscaping/alternative-methods/ hydro po nics1.htm

3. http://easyponic.com/hydroponics-a-bit-of-history/

4. http://www.ebay.com/gds/History-of-Hydroponic-cultivation/10000000001687113/g.html

5. Jensen MH (1997) Hydroponics. HortScience 32(6): 1018-1020.

6. Savvas D, Gianquinto G, Tuzel Y, Gruda N (2013) Soilless culture. Fao plant production and protection paper 217, pp: 303-354.

7. http://www.eurohydro.com / pdf/articles/gb_growing.pdf

8. http://www.homehydrosystems.com/hydroponic-systems/ aeroponics_systems.html

9. Rakocy JE (2007) Aquaponics, integrating fish and plant culture. In: TB Simmons \& JM Ebeling, (eds,). Recirculating aquaculture, Cayuga Aqua Ventures, Ithaca, USA, pp: 767-826.

10. Rakocy JE (2007) Ten guidelines for aquaponic systems. Aquaponics Journal 46: 14-17.

11. Rakocy JE, Massor MP, Losordo TM (2006) Recirculating Aquaculture Tank Production Systems: Aquaponics- Integrating Fish and Plant Culture. SRAC Publication No 454: 1-16.

12. Olympios CM (1999) Overview of soilless culture: advantages, constraints, and perspectives. In : Choukr-Allah R (ed.), Protected cultivation in the Mediterranean region, CIHEAM / IAV Hassan II, Paris, Europe, pp. $307-324$.
13. El-Behairy UA (2015) Simple Substrate Culture in Arid Lands. In: Asaduzzaman Md(ed,). Soilless Culture - Use of Substrates for the Production of Quality Horticultural Crops, p. 69-97.

14. Benoit F, Ceustermans N (1995) Horticultural aspects of ecological soilless growing methods. Acta Hort 396: 11-24.

15. Lapez I, Dorais M, Tremblay N, Gosselin A, Munuz-Carpena R (1998) Effects of varying sulfate concentrations and vapor pressure deficits (VPD) on greenhouse tomato fruit quality, foliar nutrient concentrations and amino acid components. Acta Hort 458: 303-310.

16. Bohme M (1995) Evaluation of organic, synthetic and mineral substrates for hydroponically grown cucumber. Acta Hort 401: 209217.

17. Van Os EA, Ruijs NA, Van WeeI PA (1991) Closed business systems for less pollution from greenhouses. Acta Hort 294: 49-57.

18. http://homehydrosystems.com/nutrients/nutrients_page.html

19. van Assche C, Vangheel M (1994) Special phytopathological problems in soilless cultures and substrate cultures. Acta Hort 361: 355-360.

20. Runia WTh, (1994) Disinfection of recirculation water from closed cultivation systems with ozone, Acta Hort 361: 388-396.

21. http://www.svarog-uv.org/drainage.htm

22. http://www.hydroponics.com.au/issue-38-ultra-violet-lightdisinfection/

23. Nosir W (2016) New technique for rose production in soilless culture system and disease reduction. Journal of Plant Nutrition 39(2): 181188.

24. Runia WTh (1995) A review of possibilities for disinfection of recirculation water from soilless cultures. Acta Hortic 382: 221-229.

25. Wohanka W (1995) Disinfection of recirculating nutrient solutions by slow sand filtration. Acta Hortic 382: 246-255.

26. Van Os EA, Wohanka W, Bruins M, Seidel R, (2000) Slow filtration: A technique to minimise the risks of spreading root-infecting pathogens in a closed hydroponic system. Acta Horticularae 559: 495-502.

27. Kubiak K, Błaszczyk M, Sierota Z, Tkaczyk M, Oszako T (2015) Slow sand filtration for elimination of phytopathogens in water used in forest nurseries. Scandinavian Journal of Forest Research 30(8): 664677.

28.http://www.hydroponics.com.au/disinfection-methods-anaustralian-perspective/

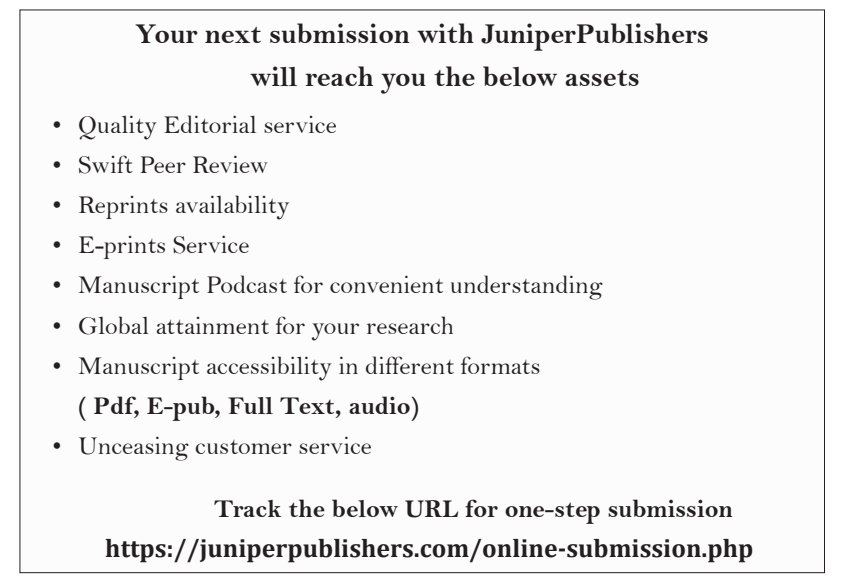


